\title{
(DON'T) HOLD YOUR BREATH: THE SOUTH AFRICAN COVID-19 VACCINE APPROVAL PROCESS AND REGULATORY FRAMEWORK
}

\section{Introduction}

The world seemed to sigh in relief in early November 2020, when it was announced that the Covid-19 vaccine developed by Pfizer and BioNTech showed itself to be 90 per cent effective in early data analysis. This announcement was followed by one from Moderna Inc that its vaccine in development was showing to be almost 95 per cent effective. Soon after, numerous other companies announced the efficacy of their respective vaccines and roll-out plans and policies were made and even implemented.

However, this sigh of relief was perhaps premature. Although these announcements were good news on the face of it, they also brought to light some concerns. The fast pace at which the vaccines were developed and made available for human use raises various ethical and legal issues as well as questions related to the safety and efficacy thereof. The correct dosage and timing of vaccination is still not fixed, vaccine expiration periods and the discovery of new variants of the Covid-19 virus has further added to these concerns (BusinessTech "Expiring Vaccines Doomed South Africa's Rollout Plans From the Start" (2021) http://www.businesstech.co.za/news/ government/467932/expiring-vaccines-doomed-south-africas-rollout-plansfrom-the-start-report/ (accessed 2021-03-18)). In addition, uncertainty exists regarding the approval process that should be followed for these vaccines. This last concern forms the focus of this note.

In South Africa, the above issues have been exacerbated by a less-thansmooth vaccine roll-out. In early February 2021, Minister of Health Dr Zweli Mkhize announced that South Africa would halt the roll-out of the Oxford/AstraZeneca vaccine, which had arrived in the country only a week before. This was due to the publication by the lead investigator in the trial describing the results as "disappointing" as shown against the South African N501Y variant of the virus. As a result, the South African government entered into negotiations with the Serum Institute of India (SII) for the Johnson \& Johnson "silver bullet" vaccine, and embarked on a new roll-out plan, involving the vaccination of healthcare workers and an evaluation of the vaccine in the field (Ellis "South Africa Switches to J\&J 'Silver Bullet' as AstraZeneca Vaccine Falters Against Local Variant of Coronavirus" (2021) http://www.dailymaverick.co.za/article/2021-02-08-south-africa-switches-tojjs-astrazeneca-vaccine-halted/ (accessed 2021-03-18)). The Johnson \& Johnson vaccine and roll-out plan, however, was not free of controversy, as it later emerged that the plan comprised not a "roll-out" of the vaccine, but 
rather a clinical trial since proper approval and registration for the use of the vaccine had not (yet) been granted (Wa Afrika "Don't Use South Africans as Vaccine Guinea Pigs" (2021) http://www.iol.co.za/sundayindependent/ news/dont-use-south-africans-as-vaccine-guinea-pigs-6bc4358e-49c2-443596a9-62142effc965 (accessed 2021-03-18)).

The National Control Laboratory for Biological Products (NCL), which is one of twelve laboratories worldwide contracted to perform vaccine testing for the World Health Organisation is in the process of testing various vaccines on behalf of the South African Health Products Regulatory Authority (SAHPRA). As variants of the virus become more prevalent, scientists are being pushed to develop vaccines targeting multiple versions of the relevant pathogens; as a result, Pfizer, Moderna, Johnson \& Johnson and AstraZeneca have started development on booster shots to accompany their vaccines (BusinessTech http://www.businesstech.co.za/news/ government/467932/expiring-vaccines-doomed-south-africas-rollout-plansfrom-the-start-report/). Although vaccinations have now started, the virus is unlikely to be eradicated soon; next-generation vaccines will have to be developed (Ellis http://www.dailymaverick.co.za/article/2021-02-08-southafrica-switches-to-jjs-astrazeneca-vaccine-halted/). Again, questions may be raised as to how these new vaccines and boosters should be approved and registered for use.

The back-and-forth roll-out of vaccines in South Africa is alarming, does little to instil a sense of trust in the powers-that-be and adds to the general confusion and concern regarding a vaccine against Covid-19. To say the least, the current situation is less than ideal. Although we might still need to hold our breath, behind a mask, a little longer, the author feels somewhat assured knowing that South Africa has a well-established procedure for the approval of new medications, although it is not exactly swift. The aim of this piece is therefore explanatory in nature as it seeks to set out the process whereby new medicines are approved and registered in South Africa.

\section{Approving a clinical trial in South Africa}

The extensive and well-defined South African framework for the regulation of medicines is established and developed by various legal instruments. These are the Medicines and Related Substances Act 101 of 1965 (Medicines Act), the National Health Act 61 of 2003 (NHA) and the South African Good Clinical Practice Guidelines (Department of Health South African Good Clinical Practice: Clinical Trial Guidelines 3ed (2019) https://sahpra.org.za/wp-content/uploads/2020/01/31828e7f4thCombined Chapt3rdRevisedNHREC_CTC_SAGCP24May2019_v3clean_Draftforcomm ent 10.07.2019.pdf (accessed 2020-11-16)) (Good Practice Guidelines). Certain other regulations and policies are also relevant to the creation and functioning of this framework and, of course, all these instruments exist under the ever-present and supreme South African Constitution (Constitution of the Republic of South Africa, 1996).

In terms of the Constitution, the State is obliged to realise progressively the socio-economic rights of all South Africans and this incudes access to healthcare as provided for by section 27 . In order to facilitate fair and equal 
access to healthcare in South Africa, the NHA provides for a structured and uniform healthcare system. Chapter 2 of the NHA also provides extensively for the rights and duties of healthcare users and personnel and includes specific provisions related to health services for experimental or research purposes (s 11 of the NHA). Chapter 9 of the NHA also provides detailed provisions related to national health research and includes the establishment of a National Health Research Ethics Council (NHREC) and research ethics committees (RECs). The NHA further provides for the creation of topicspecific regulations such as those related to research involving human participants or the various regulations regarding the NHREC and RECs. The Good Practice Guidelines serve a similar purpose to the NHA regulations as they provide for further detailed scientific and ethical standards to be met for any clinical trial involving human participants.

The Medicines Act, as amended (Medicines and Related Substances Amendment Act 72 of 2008 and Medicines and Related Substances Amendment Act 14 of 2015), establishes and empowers SAHPRA. SAHPRA is a National Department of Health entity, which assumes the roles of the Medicines Control Council (MCC) and the Directorate of Radiation Control (DRC). This means that, at its core, it is tasked with the monitoring, investigation, inspection, registration and evaluation of all health projects in South Africa against standards of safety, efficacy and quality. This includes clinical trials (South African Health Products Regulatory Authority "Who We Are" (2020) https://www.sahpra.org.za/who-we-are/ (accessed 2020-11-16)).

As the name suggests, SAHPRA is the South African regulatory authority for the regulation of health products intended for human use and the conducting of clinical trials, the licensing of manufacturers, wholesalers and distributors of medicines and medical devices. In terms of section $2 \mathrm{~B}(1)(a)-(c)$ of the Medicines Act, SAHPRA must:

"(a) ensure the efficient, effective and ethical evaluation or assessment and of medicines, medical devices and IVD's that meet the defined standards of quality, safety, efficacy and performance, where applicable;

(b) ensure that the process of evaluating or assessing and registering of medicines, medical devices is transparent, fair, objective and concluded timeously;

(c) ensure the periodic re-evaluation or re-assessment and ongoing monitoring of medicines, medical devices and IVD's."

Although not pertinent to this note, in terms of the Medicines Act read with the Hazardous Substances Act 15 of 1973, SAHPRA also regulates radiation-emitting devices and radioactive nuclides (South African Health Products Regulatory Authority "Acts and Regulations" (2020) https://www.sahpra.org.za/acts-and-regulations/ (accessed 2020-11-16)).

In South Africa, clinical trials may not be conducted, nor may medicines be marketed, prescribed, sold or administered without prior SAHPRA approval. It must be mentioned that SAHPRA is a regulatory authority and does not in and of itself undertake any trials. It approves the trials of researchers and manufacturers and ensures that the set safety, efficacy, quality and ethical standards have been met.

The process of approval is as follows and will be discussed in more detail below: 


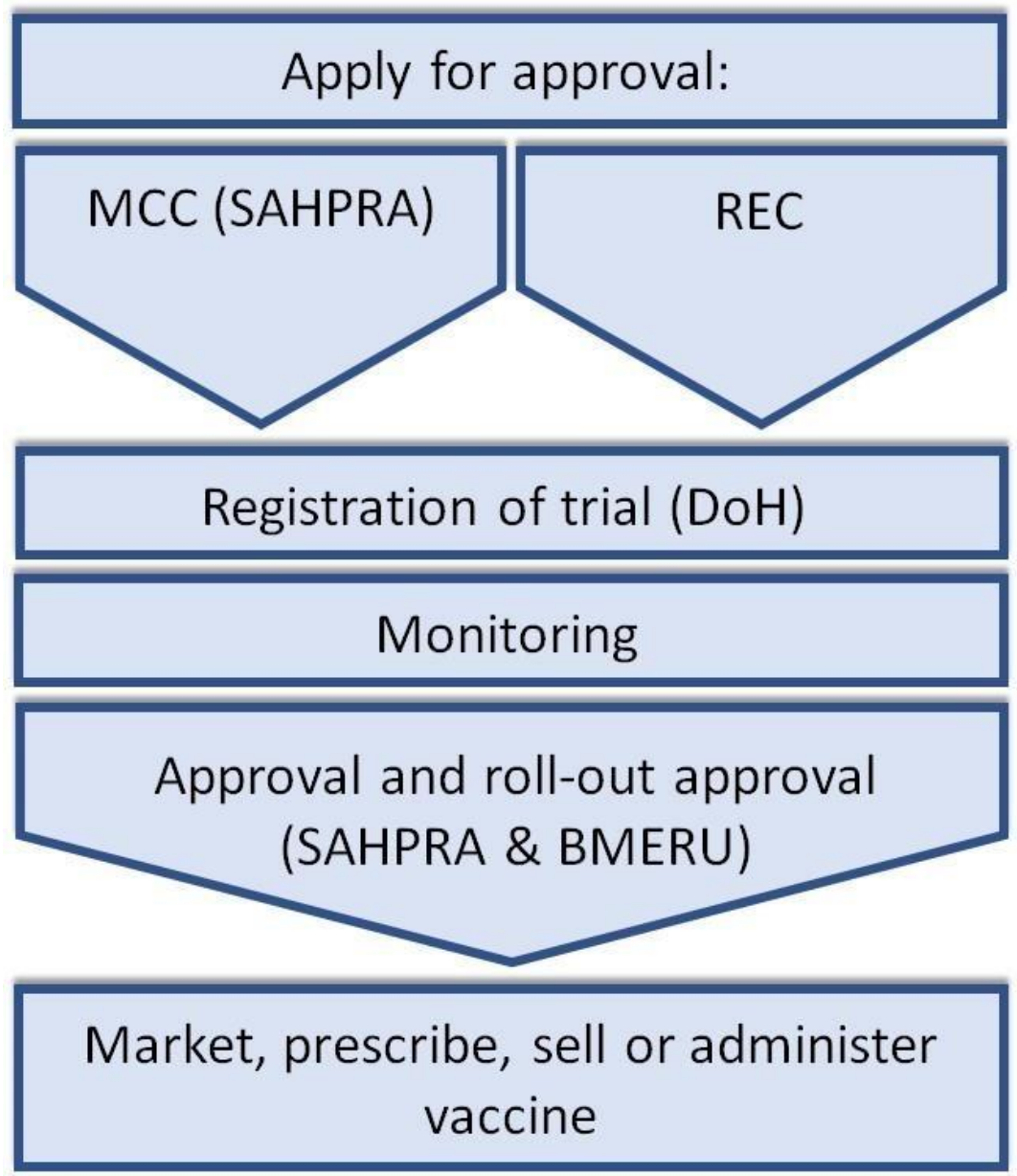

Figure 1: The approval process of a clinical trial for a Covid-19 vaccine in South Africa

\section{Approval by the Medicines Control Council}

In order to obtain approval for a clinical trial, the sponsor or principal investigator must apply to the MCC for approval of the trial to be conducted on human participants. A "sponsor" may be a pharmaceutical company or any other organisation responsible for the financing and management of a clinical trial whereas a "principal investigator" is a South African-based scientist who is responsible and accountable for the conducting and reporting of the trial.

The process of application is set out by the Regulations Relating to Medical Devices and In Vitro Diagnostic Medical Devices (IVDs) (GN 1515 in GG 40480 of 2016-12-09) which, in broad strokes, provide that: 
1. A person who desires to initiate or conduct a clinical trial must apply to the MCC on a prescribed form for authorisation to conduct such a trial.

2. Such a trial must be conducted in accordance with the Good Practice Guidelines.

3. No clinical trials may be conducted without the prior authorisation of the MCC.

4. The person responsible for conducting the clinical trial must submit progress reports to the MCC every six months from the date of commencement of the trial and 30 days after the completion or termination of the trial.

5. Adverse events must, however, be reported as soon as is practically possible.

6. The MCC may request any additional information, may inspect a clinical trial or withdraw its authorisation if it is of the opinion that the safety of the participants is compromised or the scientific rationale behind the trial has changed.

However, MCC approval is only the first step in obtaining approval as ethical approval for the trial must also be obtained.

\section{$4 \quad$ Approval by ethics committees}

All clinical trials conducted in South Africa, including multinational trials, must apply for and receive ethical approval. Ethical approval must be granted by an accredited research ethics committee (REC) based in South Africa. RECs are responsible for ensuring that ethical norms and standards are met, but also for the safeguarding of the rights of the human participants and ensuring that a clinical trial is scientifically relevant in South Africa.

As mentioned above, the NHA in section 72 provides for the establishment of a National Health Research Ethics Council (NHREC), which must:

"(a) determine guidelines for the functioning of health research ethics committees;

(b) register and audit these health research ethics committees;

(c) set norms and standards for conducting research on humans..., including ... for conducting clinical trials;

(d) adjudicate complaints about the functioning of health research ethics committees and hear any complaint by a researcher ...;

(e) refer to the relevant statutory health professional council matters involving the violation or potential violation of ethical or professional rules ...;

( $f$ institute ... disciplinary action as ... prescribed against any person found to be in violation of any norms and standards or guidelines ...; and

(g) advise the national department and provincial departments on any ethical issues concerning research." (s 72(6) of the NHA)

Section 69 of the NHA provides for the establishment of the National Health Research Committee. This committee must:

"(a) determine the health research to be carried out by public health authorities; $(b)$ ensure that health research agendas and research resources focus on priority health problems; $(c)$ develop and advise the Minister on the 
application and implementation of an integrated national strategy for health research; and (d) coordinate the research activities of public health authorities." (s 69(3) of the NHA)

Specific provision is also made for research on or experimentation with human participants in section 71 of the NHA. This section provides for a wide variety of matters, including the conditions for research involving human participants in general, research involving a minor for therapeutic purposes, and research involving a minor for non-therapeutic reasons. The provisions found in the NHA are also supplemented by various regulations made in terms of the Act. Section 11, which provides for health services for experimental or research purposes, may also be relevant.

Currently, RECs must pay additional attention to Covid-19 trials, which are categorised as involving innovative therapy and, owing to this classification, additional control and review measures are imposed on the trial (see in general, De Vries "Research on COVID-19 in South Africa: Guiding Principles for Informed Consent" 2020 110(7) SAMJ 635-639 https://doi.org/10.7196/SAMJ.2020.v110i7.14863). Once ethical approval is granted, the clinical trial may be registered.

\section{$5 \quad$ Registration of clinical trial}

After MCC and ethical approval has been obtained, the person responsible for the trial, the sponsor or principal investigator, must apply to the Department of Health (DoH) to have the trial registered.

The DoH must record the trial on the South African National Clinical Trial Register and award the trial a number. Only once the trial has been registered with the $\mathrm{DoH}$ and awarded its unique number may the trial commence (South African National Clinical Trial Register and National Health Research Ethics Committee "South African National Clinical Trial Registry (SANCTR) and National Health Research Ethics Committee (NHREC)" (2020) http://www.crc.uct.ac.za/sites/default/files/image_tool/ images/53/documents/Reg/CRC\%20website_Regulatory\%20Content_updat ed\%2020171204_SANCTR_NHREC.pdf (accessed 2020-11-16)). At this stage, the monitoring plan also takes effect.

\section{$6 \quad$ Monitoring plan}

The sponsor or principal investigator must have in place a monitoring plan that stipulates the review and monitoring of the trial. Normally, such review is done on a six-monthly basis as clinical trials may last years. However, owing to the rapidly changing dynamics of Covid-19, SAHPRA currently allows for an expedited two-week abridged Covid-19 interim progress report form for clinical trials. This report deals specifically with safety and futility monitoring (South African Health Products Regulatory Authority "Clinical Trials" (2020) https://www.sahpra.org.za/clinical-trials/ (accessed 2020-11-16)).

The prescribed form must be completed two-weekly from the date of approval of the clinical trial and even if participant enrolment has not yet started. It does not, however, replace the required six-monthly progress report. 


\section{$7 \quad$ Approval granted and roll-out}

After the trial delivers fruitful results - that is, the successful development of a vaccine - the vaccine must be registered with SAHPRA. Only then may it be marketed, sold, prescribed or administered in South Africa, regardless of any foreign approval thereof by another country. This means, for example, that even if the Pfizer BioNTech vaccine is fully approved abroad by the American Food and Drug Administration (FDA), it will still have to be locally approved and registered by SAHPRA. Note that, should a foreign regulatory authority that is recognised by SAHPRA (such as the FDA) already have approved the vaccine, SAHPRA may allow for expedited approval and registration within South Africa.

The registration of a new biological medicine, which includes a vaccine, is undertaken by the Biological Medicines Evaluation and Research Unit (BMERU), a sub-unit of SAHPRA. BMERU is responsible for the evaluation of applications for the registration of biological medicines, the evaluation of applications for amendments to registered biological medicines, communicating with the pharmaceutical industry on matters of policy, the establishment of regulatory frameworks for the use of blood products and stem cells, and the establishment of pertinent regulatory frameworks for vaccines (South African Health Products Regulatory Authority "Biological Medicines Evaluation and Research Unit" (2020) https://www.sahpra.org.za/biological-products/ (accessed 2020-11-16)).

Once SAHPRA and BMERU have concluded their evaluation of the registration application, taking into account any expert committee recommendations and all required documentation, it will decide whether a new biological medicine meets all requirements for registration.

If so, the medicine will be registered and may then be made available in South Africa.

\section{Conclusion}

This note has explained the process to be followed in approving new medication for human use within South Africa. Although the South African framework for the approval of new medication, such as a Covid-19 vaccine is clear cut, the virus has proved to be wiley; and constant vaccine improvement and development will be necessary. This in turn will make the processes discussed above even more important so as to ensure safe and efficient, legal and ethically sound vaccine availability. In the meantime, we wait with masked and bated breath. 